\title{
Study on the major welfare problems of dairy cows from the Galicia region (NW Spain)
}

\author{
Ana Bugueiro, · José Pedreira • Francisco Javier Diéguez
}

A Bugueiro (Corresponding author) - FJ Diéguez

Departamento de Anatomía y Producción Animal, Facultad de Veterinaria de Lugo, Universidade de Santiago de Compostela, Campus Universitario s/n, 27002 Lugo, Spain. email: ana.bugueiro@rai.usc.es

\author{
J Pedreira \\ Piensos PIGARCRE S.L., Campo da Feira, 13 (Lestón), \\ Paiosaco, 15145 Laracha, Spain.
}

Received: March 23, 2018 - Revised: May 08, 2018 • Accepted: May 08, 2018

\begin{abstract}
The aim of the present paper was to evaluate the dairy cattle welfare in a population from the Galicia region (NW Spain) according to the Welfare Quality ${ }^{\circledR}$ protocol guidelines. For this purpose, 37 dairy farms were randomly selected. The on-farm welfare was evaluated according to Welfare Quality ${ }^{\circledR}$ guidelines. At principle level, the categorical classification indicated that regarding "good feeding" $5.4 \%(0 \%-13.1 \%)$ of the farms were classified as "excellent", $29.7 \% \quad(14.3 \%-45.3 \%) \quad$ "enhanced", $48.6 \%$ (31.7\%-65.5\%) "acceptable" and 16.2\% (3.8\%-28.7\%) "not classified". As regards "good housing", 5.4\% (0\%-13.1\%) were classified as "excellent", $64.9 \% \quad(48.7 \%-81.0 \%)$ "enhanced" and 29.7\% (14.3\%-45.2\%) "acceptable". 100\% (100\%-100\%) were considered "acceptable" for the "good health" principle. Finally, for "appropriate behaviour" $2.7 \%$ (0-8.2\%) was classified as "enhanced", $13.5 \%$ (1.9\%-25.1\%) "acceptable" and 83.8\% (71.3\%-96.2\%) "not classified". Overall, according to the Welfare Quality ${ }^{\circledR}$ protocol $94.6 \%$ (86.5\%-100\%) farms were classified as "acceptable", $2.7 \%$ (0-8.2\%) as "enhanced" and 2.7\% (0-8.2\%) "not classified". In conclusion, farms from Galicia could only be considered as "acceptable" in terms of animal welfare, presenting many areas for improvement. The principle scored at its lowest has been "appropriate behaviour", presenting it as an issue not properly taken into the farmer consideration. Another warning aspect is the management of disease, marked on a bad score for "good health": As it seems, farmers should include new health-control plans providing better prevention of disease, and include anaesthetic and analgesic plans for dehorning.
\end{abstract}

Keywords: dairy cattle, welfare assessment, Welfare Quality ${ }^{\circledR}$

\section{Introduction}

The importance of animal welfare is well recognized by citizens and that animal welfare is an increasingly important factor in food purchasing decisions (Martelli 2009;
Verbeke 2009; Napolitano et al 2010; Vanhonacker and Verbeke 2014; Clark et al 2016).

In cases such as dairy cattle both consumers and producers benefit from the consideration of animal welfare. For producers, well-treated cows result in disease prevention and more milk being produced: welfare decreases instances of disease, injury, and malnutrition. Good welfare can be indicated by high levels of growth and reproduction, normal functioning of physiological and behavioural processes, and ultimately by a high rate of longevity and biological fitness (Fraiser and Broom 1990).

In the EU, the project of Welfare Quality ${ }^{\circledR}$ under the title "Integration of animal welfare in the food industry chain" fits perfectly in the purpose of the undertaken research. It is a European project developed under standardised methods of expert assessing animal welfare and standardised methods of integrating this information. It enables farms and slaughterhouses to be assigned to one of four categories and it means a suitable assessment since it includes the innovative focus on animal-based measurements. The welfare of an animal is a characteristic of an animal and not something given by the human (Broom 2006). Welfare scores are calculated based on the severity of problems and their prevalence (Botreau et al 2009).

The aim of the present paper was to identify the welfare problems of dairy cows from the Galicia region (NW Spain) according to the Welfare Quality ${ }^{\circledR}$ protocol guidelines.

\section{Materials and Methods}

Area description and herd surveyed

Galicia (NW Spain) is the biggest dairy region in Spain; in 2016 it was responsible for $37 \%$ of the milk produced in Spain, constituting approximately $1.9 \%$ of the milk produced in the European Union.

The study was carried out in 37 dairy herds randomly selected among the population of dairy farms from Galicia. 
The mean herd size of the surveyed herds was 61 lactating cows (standard deviation $=40.3) .31$ out of $37(83.8 \%)$ farms were free stalls whereas the remaining $6(16.2 \%)$ were tie stalls. All cows were Holstein breed.

\section{Welfare assessment}

On farm welfare was evaluated according to the Welfare Quality ${ }^{\circledR}$ protocol (Welfare Quality ${ }^{\circledR}$ consortium 2009) by two assessors, both Veterinarians specialized in dairy cattle and trained accord the Welfare Quality ${ }^{\circledR}$ guidelines (Table 1).

The "good human-animal relationship criteria" was performed in the moment after milking when it is best to assess the "avoidance distance" that has to exist between the assessor and the animal when attempting touch.

After this test, the assessor would observe the collective of animals interacting. Up to the herd size, the hold time period of observation has to be at least 1 hour. At this moment the number of animals lying entirely or half in the lying area, eating or drinking is recorded. This leads to the results of "absence of prolonged thirst" and "comfort around resting" criteria. During the recording time, the criterion of "expression of social behaviour" is additionally annotated (Table 2). Also, every instance of coughing is checked each interval of $15 \mathrm{~min}$ for its inclusion in the "absence of disease" score.
There is a hold time of observation which needs special attention: that of a cow lying down to count the seconds it needs to perform this ("comfort around resting criteria").

The third step is to go next to the animals to check individually different characteristic from it. At the same point, all the integument alterations are checked. To finalise any kind of disease indicator is counted. All this measurements will be included in the "absence of disease" score.

Once finished, it is advisory to check how clean the water points are, to be included as an indicator of "absence of thirst" criteria.

The last step asks to hold a short interview with the farmer to be informed about the tethered management. Data to integrate under the "absence of pain by management procedures", "absence of disease", "ease of movement" and "expression of social behaviour criteria" should have been collected after interviewing.

\section{Data analysis}

Data were processed with SPSS 11.0. Descriptive statistics were estimated for the different measures collected on the farms. Besides, the Pearson correlation coefficient was used to determine whether exits correlation between these measures. Descriptive statistics were also estimated for the scores obtained in the different criteria and principles considered in the protocol.

Table 1 Welfare Quality ${ }^{\circledR}$ principles, criteria and measures, and type of data produced for dairy cattle

\begin{tabular}{|c|c|c|}
\hline Welfare principle & Welfare criteria & Measures \\
\hline \multirow[t]{2}{*}{ Good feeding } & Absence of prolonged hunger criteria & Body condition score (Very lean $<2.25 \mathrm{BC}$ ) \\
\hline & Absence of prolonged thirst criteria & $\begin{array}{l}\text { Water provision, Cleanliness of water points, Water flow, } \\
\text { Functioning of water points }\end{array}$ \\
\hline \multirow[t]{3}{*}{ Good housing } & Comfort around resting & $\begin{array}{l}\text { Time needed to lie down, Animals colliding with housing } \\
\text { equipment during lying down, Animals lying partly or } \\
\text { completely outside the lying area, Cleanliness of udder, } \\
\text { Flank/upper legs and lower legs }\end{array}$ \\
\hline & Thermal comfort & No measure for dairy cattle \\
\hline & Ease of movement criteria & Presence of tethering, Access to outdoor loafing area or pasture \\
\hline \multirow[t]{3}{*}{ Good health } & Absence of injuries criteria & $\begin{array}{l}\text { Lameness (loose house animals), Lameness (tied animals), } \\
\text { Integument alteration (hairless parches and lesions swelling) }\end{array}$ \\
\hline & Absence of disease criteria & $\begin{array}{l}\text { Coughing, Nasal discharge, Ocular discharge, Hampered } \\
\text { respiration, Vulvar discharge, Milk somatic cell count, } \\
\text { Mortality, Dystocia, Downer cows }\end{array}$ \\
\hline & $\begin{array}{l}\text { Absence of pain by management } \\
\text { procedures criteria }\end{array}$ & Disturbing/dehorning, Tall docking \\
\hline \multirow{4}{*}{$\begin{array}{l}\text { Appropriate } \\
\text { behaviour }\end{array}$} & Expression of social behaviour criteria & Agonistic behaviour \\
\hline & Expression of other behaviour criteria & Access to pasture \\
\hline & Good human-animal relationship criteria & Avoidance distance at the feeding place \\
\hline & Positive emotional state & Behaviour observations \\
\hline
\end{tabular}




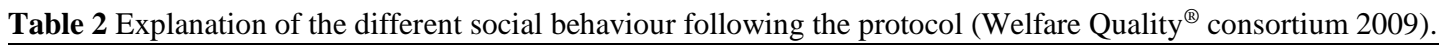

Displacement Interaction involving physical contact and provoques the receiver gives up its position waking away for at least half an animal-length or stepping aside for at least one animal-width.

Head butts Butting, hitting, thrusting, striking, pushing and the receiver does not give up its present position

Fighting Two contestants vigorously pushing their heads against each other while stemming their feet into the ground

Chasing up An animal actor uses forceful physical contact, being either butting or pushing or shoving, against a lying animal which stands the receiver rise

\section{Results}

The estimations of the mean values of the animal measurements recorded during the farm visits, along with their confidence intervals, are presented in Table 3. Measurements that correlate significantly, with their corresponding $\rho$ values are presented in Table 4.

From the measurements recorded in the farms, the scores for each of the eleven welfare criteria reflected in the protocol were also estimated for the studied population (thermal comfort was not assessed). These scores are summarized in Table 5.

The worst scores were obtained for "expression of social behaviours", "expression of other behaviours", "positive emotional state" and "absence of pain induced by management procedures". These four principles obtained mean scores below 30 .

Table 3 Descriptive statistics (mean and 95\% confidence interval) of the measures collected on the 37 farms.

\begin{tabular}{|c|c|}
\hline Variable & Value (95\% C.I.) \\
\hline Prevalence of very lean cows, $\%$ & $19.40(14.44-24.36)$ \\
\hline$\%$ with clean or partly dirty water points & $64.90(49.00-81.00)$ \\
\hline$\%$ in which water flow was adequate & $70.27(54.22-82.51)$ \\
\hline$\%$ in which water flow was partly adequate & $21.62(11.39-37.20)$ \\
\hline Duration lying down behaviour (s), mean & $5.73(5.36-6.10)$ \\
\hline Prevalence of collisions with equipment during lying down, $\%$ & $11.08(5.30-16.87)$ \\
\hline Prevalence of animals lying partly or completely outside the lying area, $\%$ & $2.62(0.75-4.50)$ \\
\hline Prevalence of animals with dirty legs, $\%$ & $72.19(61.78-82.59)$ \\
\hline Prevalence of animals with dirty udders, $\%$ & $36.47(26.42-46.51)$ \\
\hline Prevalence of animals with dirty flanks, $\%$ & $53.25(42.55-63.95)$ \\
\hline$\%$ of farms with outdoor loafing area available & $10.86(4.29-24.71)$ \\
\hline$\%$ of farms that allowed access to pasture & $24.32(13.36-40.12)$ \\
\hline Prevalence of lame cows, $\%$ & $3.20(1.83-4.56)$ \\
\hline Prevalence of severely lame cows, $\%$ & $10.18(6.99-13.37)$ \\
\hline Prevalence of mild integument alterations, $\%$ & $21.42(15.71-27.12)$ \\
\hline Prevalence of severe integument alterations, $\%$ & $27.67(21.77-33.56)$ \\
\hline Frequency of coughing per cow per 15 min & $0.37(0-0.89)$ \\
\hline Prevalence of nasal discharge, $\%$ & $5.26(3.43-7.09)$ \\
\hline Prevalence of ocular discharge, $\%$ & $1.03(0.39-1.66)$ \\
\hline Prevalence of increased respiratory rate, $\%$ & $1.42(0.47-2.37)$ \\
\hline Prevalence of diarrhoea, $\%$ & $3.23(1.69-4.77)$ \\
\hline Prevalence of vulvar discharge, $\%$ & $2.85(1.76-3.95)$ \\
\hline Prevalence of mastitis, $\%$ & $0.35(0-0.73)$ \\
\hline Prevalence of involuntary culling, $\%$ & $4.23(2.76-5.70)$. \\
\hline Prevalence of dystocia, $\%$ & $4.50(2.75-6.25)$ \\
\hline Prevalence of downer cows, $\%$ & $2.89(1.71-4.07)$ \\
\hline$\%$ of farms that dehorn calves & $98(96.2-100)$ \\
\hline$\%$ of farms applied tail docking & $0(0-0)$ \\
\hline Frequency of butts per cow per hour, mean & $3.48(2.67-4.30)$ \\
\hline Frequency of other agonistic behaviours per cow per hours, mean & $21.22(15.90-26.56)$ \\
\hline Prevalence of animals that can be touched, $\%$ & $65.87(60.41-71.34)$ \\
\hline Prevalence of animals approached at $<0.5 \mathrm{~m}, \%$ & $0.94(0-2.17)$ \\
\hline Prevalence of animals approached at $<1$ and $>0.5 \mathrm{~m}, \%$ & $1.10(0-2.36)$ \\
\hline Prevalence of animals that cannot be touched, $\%$ & $31.94(26.15-37.72)$ \\
\hline
\end{tabular}


Most famers dehorn calves by chemical $(82.9 \%)$ or thermal $(17.1 \%)$ procedures, however, only $2.85 \%$ used analgesics and $0 \%$ anaesthetics.

On the contrary, the main strengths regarding welfare are related to "ease of movements" and "absence of prolonged thirst".

From the previous data, scores were estimated at principle level. A descriptive analysis of these figures is presented in Table 6.

At principle level, the categorical classification indicated that regarding "good feeding" 5.4\% (0\%-13.1\%) of the farms were classified as "excellent", $29.7 \%(14.3 \%$ -
45.3\%) "enhanced", 48.6\% (31.7\%-65.5\%) "acceptable" and $16.2 \%(3.8 \%-28.7 \%)$ "not classified". As regards "good housing", 5.4\% (0\%-13.1\%) were classified as "excellent", $64.9 \%$ (48.7\%-81.0\%) "enhanced" and 29.7\% (14.3\%-45.2\%) "acceptable". $100 \% \quad(100 \%-100 \%)$ were considered "acceptable" for the "good health" principle. Finally, for "appropriate behaviour" $2.7 \%(0-8.2 \%)$ were classified as "enhanced", $13.5 \%$ (1.9\%-25.1\%) "acceptable" and 83.8\% (71.3\%-96.2\%) "not classified".

Overall, according to the WQ protocol $94.6 \%(86.5 \%$ $100 \%)$ farms were classified as "acceptable", $2.7 \%(0-8.2 \%)$ as "enhanced" and 2.7\% (0-8.2\%) "not classified".

Table 4 Pearson correlation coefficients (along with the p-values) for those measures that correlated significantly.

\begin{tabular}{lcc}
\hline Measures & $\rho$ & $\mathrm{p}$-value \\
\hline \% lean cow/\% severely lame cows & 0.386 & 0.018 \\
\% lying down movements with collisions/\% severely lame cows & 0.398 & 0.015 \\
\% cows with dirty legs/\% with severe integument alterations & 0.349 & 0.035 \\
\% cows with dirty flanks/\% with severe integument alterations & 0.329 & 0.047 \\
\% cows with dirty flanks/\% severely lame & 0.522 & 0.001 \\
\% cows with dirty udder/\% severely lame & 0.458 & 0.004 \\
\% cows with dirty legs/\% mortality last 12 months & 0.348 & 0.035 \\
\% cows with dirty udder//\% mortality last 12 months & 0.369 & 0.025 \\
\% cows with dirty flanks//\% mortality last 12 months & 0.398 & 0.015 \\
\% severely lame cows/\% cows that can be touched & 0.363 & 0.027 \\
frequency of coughing/frequency of aggressive events (except butts) & 0.512 & 0.001 \\
\% cows with increased respiratory rate/frequency of aggressive events (except butts) & 0.438 & 0.007 \\
\hline
\end{tabular}

Table 5 Descriptive statistics (mean with 95\% confidence interval and percentiles) on criterion scores from the 37 dairy farms (expressed on a 0 to100 value scale in which 0 correspond to the worst situation, 50 to a neutral situation and 100 to the best situation).

\begin{tabular}{|c|c|c|c|c|c|c|}
\hline & \multirow{2}{*}{$\begin{array}{c}\text { Mean } \\
(95 \% \text { confidence interval) }\end{array}$} & \multicolumn{5}{|c|}{ Percentiles } \\
\hline & & 10 & 25 & Median & 75 & 90 \\
\hline Absence of prolonger hunger & $40.98(32.86-49.11)$ & 14.34 & 29.95 & 37.50 & 55.75 & 82.22 \\
\hline Absence of prolonger thirst & $69.00(56.60-81.39)$ & 26.20 & 32.00 & 100.00 & 100.00 & 100.00 \\
\hline Comfort around resting & $44.66(38.23-51.09)$ & 14.72 & 35.10 & 45.10 & 54.75 & 66.44 \\
\hline Ease of movement & $92.35(84.86-99.83)$ & 34.00 & 100.00 & 100.00 & 100.00 & 100.00 \\
\hline Absence of injuries & $49.87(42.49-57.25)$ & 24.58 & 32.70 & 43.20 & 66.55 & 83.58 \\
\hline Absence of diseases & $49.41(41.94-56.89)$ & 24.70 & 30.20 & 44.80 & 60.60 & 86.00 \\
\hline $\begin{array}{l}\text { Absence of pain induced by } \\
\text { management procedures }\end{array}$ & $26.31(20.18-32.44)$ & 20.00 & 20.00 & 20.00 & 26.35 & 30.60 \\
\hline $\begin{array}{l}\text { Expression of social } \\
\text { behaviours }\end{array}$ & $4.68(0.00-10.23)$ & 0.00 & 0.00 & 0.00 & 0.00 & 12.74 \\
\hline Expression of other behaviours & $16.47(4.60-28.33)$ & 0.00 & 0.00 & 0.00 & 0.00 & 100.00 \\
\hline $\begin{array}{l}\text { Good human-animal } \\
\text { relationship }\end{array}$ & $41.02(34.74-47.30)$ & 21.20 & 27.50 & 32.90 & 51.35 & 76.00 \\
\hline Positive emotional state & 23.80 & 23.80 & 23.80 & 23.80 & 23.80 & 23.80 \\
\hline
\end{tabular}

\section{Discussion}

Most farms in the studied population were found globally "acceptable" according to the Welfare Quality ${ }^{\circledR}$ protocol, which means that there is a significant scope for improving many issues affecting dairy cattle welfare.

The mean score estimated in the present paper for the principle "good feeding" was 44.38; on the whole, farms from Galicia, can only be considered as "acceptable". The main drawback for this score was the "percentage of lean cows" (affecting, in turn, the criterion of "absence of prolonged hunger"). This percentage reaches $19.4 \%$ in the studied population. On the contrary, as regards "absent of prolonged thirst" more than $50 \%$ of the farms had scores of 100 . No previous studies reported these welfare measures in other Spanish populations. However, in the border country of France, de Boyer et al (2014) found a lower result when using also the Welfare Quality ${ }^{\circledR}$ protocol. Differences could be 
partly related to differences in breed (in France included Montbéliarde besides Holstein) or farms design.

A moderate positive correlation was found between $\%$ of lean and \% of severely lame cows in the present study. Previously, a positive correlation was also found between BCS and locomotion score, since lame cows have more difficulty accessing food (Bowell et al 2003).

Overall, the studied population could be classified as "enhanced" for the second principle: "good housing". The time needed to lying down in the surveyed herds was close to normal. The $\%$ of collisions during lying down seems to be moderately correlated with the $\%$ presence of severely lame cows. The main limitation regarding this principle was related to cleanliness, in which the farms on average showed serious problems. Cattle cleanliness affects hygienic milk production and thermoregulation; manure can also etch into the skin and cause subclinical infection and lesions, issues of concern for animal welfare (Hauge et al 2012). In this concern were found significant moderate correlations between cleanliness and the $\%$ of severe integument alterations and the $\%$ of severe lameness.

When assessing the "good health" principle, the data reflecting "absent of injuries" indicated a $3.20 \%$ of lame cows and $10.18 \%$ of severely lame. Most recent studies on lameness showed very different statistics. In Irish dairy herds the lameness prevalence ranged from 9-17\% (Somers and O'Grady 2015). In the UK, the estimated prevalence of lame and severely lame cows was $36.8 \%$ (Barker et al 2010). In Austria the median prevalence of severely lame cows was $4 \%$ (Rouha-Mülleder et al 2009). Assessing the cattle welfare in France, de Boyer et al (2014) indicated that the median percentage of lameness was $70.9 \%$. Integument alterations are also common findings in cattle, reflecting conflict between the animals and their housing equipment. Following the protocol, $21.42 \%$ of the cows in Galicia had mild alterations and $27.67 \%$ severe. Brenninkmeyer et al (2015), in a study carried up in Germany indicated a median farm prevalence up to $83 \%$ for different integument lesions. In France, the estimated median prevalence in cows for these kind of lesions was $33.1 \%$ (de Boyer et al 2014).

Tail docking, is not allowed by the Galicia regional regulations. Although, disbudding of calves is a widespread practice in Galicia. However, in Galicia, a dehorning procedure is performed always without anaesthesia and almost always without analgesia. The administration of a local anaesthetic and analgesia reduces de rise in cortisol observed after dehorning and behavioural indications of pain during the action (McMeekan et al 1998; Sylvester et al 1998; Faulkner and Weary 2000; Vickers 2005; Stilwell et al 2009; Stock et al 2013).

Table 6 Descriptive statistics (mean with 95\% confidence interval and percentiles) on principle scores from the 37 dairy farms (expressed on a 0 to100 value scale in which 0 correspond to the worst situation, 50 to a neutral situation and 100 to the best situation).

\begin{tabular}{lcccccc}
\hline & Mean & \multicolumn{5}{c}{ Percentiles } \\
\cline { 3 - 7 } & $(95 \%$ confidence interval) & 10 & 25 & Median & 75 & 90 \\
\hline Good feeding & $44.38(37.06-51.70)$ & 16.76 & 28.50 & 45.40 & 57.50 & 73.14 \\
Good housing & $61.75(56.65-66.85)$ & 33.14 & 37.00 & 65.40 & 70.90 & 77.18 \\
Good health & $33.49(30.46-36.51)$ & 22.44 & 25.75 & 32.60 & 40.90 & 46.08 \\
Appropriate behaviour & $13.27(8.82-17.71)$ & 6.20 & 6.90 & 8.10 & 14.35 & 28.36 \\
\hline
\end{tabular}

"Appropriate behaviour" is the worst rated of all principles (on average the farms were "not classified"). This is the basic relation to the expression of social behaviours and other behaviours. Bovine is a social species; animals in groups form a dominance hierarchy. In the studied population only $24.3 \%$ of the farms allowed access to pasture, which correspond mainly with those in tie-stalls. Longer pasture access ( 8 compared to 4 hours) improved the relaxing effects, indicated through lower heart rates and less aggressive interactions (Irrange and Knierim 2012). In general animal to animal interaction seems to be the mean limitation for "appropriate behaviour" in the studied population since human-animal interaction, measured through avoidance distance, had an acceptable score. In the present paper avoidance distance was also correlated to lameness. On the contrary, Mülleder et al (2003) found this correlation but they could not conclude that lameness correlated significantly with avoidance distance.

\section{Conclusions}

In conclusion, farms from Galicia could only be considered as "acceptable" in terms of animal welfare, presenting many areas for improvement. The principle scored at its lowest has been appropriate behaviour, presenting it as an issue not properly taken into farmer consideration. Another warning aspect is the management of disease, marked on a bad score for good health: As it seems, farmers should include new health-control plans providing better prevention of disease, and including anaesthetic and analgesic plans for dehorning. In spite of farm being conscious of good housing, it can be concluded that dairy cows in Galicia are according to the protocol, exposed to important problems related to health and behaviour.

\section{Acknowledgements}


Thanks are due to Nate Tabor and Pepa Bugueiro for their patience and proof reading. To all farms part of this research.

\section{References}

Barker ZE, Leach KA, Whay HR, Bell NJ, Main DC (2010) Assessment of lameness prevalence and associated risk factors in dairy herds in England and Wales. Journal of Dairy Science 93:932941.

Botreau R, Veissier I, Perny P (2009) Overall assessment of animal welfare: Strategy adopted in Welfare Quality ${ }^{\circledR}$. Animal Welfare 18:363-370.

Boyer des Roches A, Vessier I, Coignard M, Bareille N, Guatteo R, Capdeville J, Gilot-Fromont E, Mounier L (2014) The major welfare problems of dairy cows in French commercial farms: an epidemiological approach. Animal welfare 23:467-478.

Bowell VA, Rennie LJ, Tierney G, Lawrence AB and Haskell MJ (2003) Relationship between building design, management system and dairy cow welfare. Animal Welfare 12:547-552.

Broom DM (2006) Behaviour and welfare in relation to pathology. Applied Animal Behaviour Science 97:73-83.

Brenninkmeyer C, Dippel S, Brinkman J, March S, Winckler C, Knierim U (2015) Investigating integument alterations in cubicle housed dairy cows: which types and locations can be combined? Animal 6:1-7.

Clark B, Stewart GB, Panzone LA, Kyriazakis I, Frewer LJ (2016) A systematic review of public attitudes, perceptions and behaviours towards production diseases associated with farm animal welfare. Journal of Agriculture and Environmental Ethics 29: 455-478.

Faulkner PM and Weary DM (2000) Reducing pain after dehorning in dairy calves. Journal of Dairy Science. 83:2037-2041.

Fraiser F and Broom DM (1990) Farm animal behaviour and welfare. Baillière Tindall: London, UK.

Hauge SJ, Kielland C, Ringdal G, Skjerve E, Nafstad O (2012) Factors associated with cattle cleanliness on Norwegian dairy farms. Journal of Dairy Science 95:2485-2496.

Irrange N and Knierim U (2012) Can pasture access contribute to reduced agnostic interactions and relaxation in the loose housing barn in horned dairy cows? In: Waiblinger S, Winckler C, Gutmann A (eds.) Proceedings of the $46^{\text {th }}$ congress of the international society of animal ethology International Society for Applied Ethology: Vienna, Austria, pp 97.

Martelli G (2009) Comsumer's perception of farm animal welfare: a Italian and European perspective. Italian Journal of Animal Science $8: 31-41$.

McKeekan CM, Stafford KJ, Mellor DJ (1998) Effects of regional analgesia and/or a non-steroidal anti-inflammatory analgesic on the acute cortisol responses to dehorning in calves. Research in Veterinary Science 64:147-15.

Müllerder C, Troxler J, Waiblinger S (2003) Methodological aspects for the assessment of social behavior and avoidance distance on dairy farms. Animal Welfare 12:579-584.

Napolitano F, Girolami A, Braguieri A (2010) Consumer liking and willingness to pay for high welfare animal-based products. Trends in Food Science \& Technology 21:537-543.
Rouha-Mülleder C, Iben C, Wagner E, Laaha G, Troxler J, Waiblinger S (2009) Relative importance of factors influencing the prevalence of lameness in Asutralian cublicle loose-housed dairy cows. Preventive Veterinary Medicine 92:123-133.

Somers J and O'Grady L (2015). Foot lesions in lame cows on 10 dairy farms in Ireland. Irish Veterinary Journal 68:10.

Stilwell G, Carvalho RCD, Lima MS, and Broom DM (2009) Applied animal behaviour science. Applied Animal Behaviour Science 116:35-44.

Stock ML, Baldridge SL Griffin D and Coetzee JF (2013) Bovine dehorning: Assessing pain and providing analgesic management. Veterinary Clinics: Food Animal Practice 29:103-133.

Sylvester SP, Stafford KJ, Mellor DJ. Bruce RA, Ward RN (1998). Acute cortisol responses of calves to four methods of dehorning by amputation. Australian Veterinary Journal 76:123-126.

Vanhonacker F and Verbeke W (2014) Public and consumer policies for higher welfare food products: Challenges and opportunities. Journal of Agricultural and Environmental Ethics 27:153-171.

Verbeke W (2009) Stakeholder, citizen and consumer interests in farm animal welfare. Animal Welfare 18:325-333.

Vickers KJ, Niel L, Kiehlbauch LM, Weary DM (2005). Calf response to caustic paste and hot iron dehorning using sedation with and without local anesthetic. Journal of Dairy Science 88:1454-1459.

Welfare Quality ${ }^{\circledR}$ consortium (2009) Welfare Quality ${ }^{\circledR}$ applied to dairy cows Welfare Quality ${ }^{\circledR}$ consortium (ed) Welfare Quality ${ }^{\circledR}$ : Assessment protocol for cattle ASG Veehouderij BV: Lelystad, The Netherlands, pp 69-111. 